\title{
Protein Kinase A and C Site-specific Phosphorylations of LAP (NF-IL6) Modulate Its Binding Affinity to DNA Recognition Elements
}

\author{
Christian Trautwein, ** Peter van der Geer," Michael Karin, ${ }^{*}$ Tony Hunter, ${ }^{*}$ and Mario Chojkier* \\ *Departments of Medicine (Veterans Affairs Medical Center) and ${ }^{\ddagger}$ Pharmacology, and Center for Molecular Genetics, University of \\ California, San Diego, California 92161; and ${ }^{\S}$ Salk Institute for Biological Studies, La Jolla, California 92037
}

\begin{abstract}
LAP (NF-IL6 or C/EBP $\beta$ ), is a liver transcriptional activator protein that confers liver-specific gene expression. Because LAP has a characteristic phosphoacceptor sequence for cAMP-dependent protein kinase A (PKA), we tested if in vitro phosphorylation of LAP by PKA modulates its interaction with specific DNA sequences. The major PKA phosphorylation site of LAP was identified as Ser ${ }^{105}$, which is a predicted PKA site. As expected, this PKA phosphorylation site disappears after mutation of Ser ${ }^{105}$ to Ala. Kinetic studies with LAP and LAP $\operatorname{Asp}^{105}$ (which mimics a phosphoserine residue) demonstrated that phosphorylation of Ser ${ }^{105}$ itself has no effect on DNA binding. Phosphorylation of other sites by PKA, identified in the region between $\operatorname{Ser}^{173}$ and $\operatorname{Ser}^{223}$ and at $\operatorname{Ser}^{240}$, by analysis of truncated and mutated LAP peptides, resulted in an inhibition of DNA binding. LAP was also phosphorylated by purified protein kinase $C$ in vitro, and the major phosphoacceptor was shown to be Ser ${ }^{240}$ within the DNA-binding domain of LAP. Phosphorylation of LAP at this residue or introduction of a $\operatorname{Ser}^{240}$ to Asp mutation resulted in marked decrease in its binding to DNA. These results suggest that site-specific phosphorylations of LAP modulate transactivation of its target genes. ( $J$. Clin. Invest. 1994. 93:2554-2561.) Key words: liver-specific gene expression - albumin gene transcription - acute-phase genes $\bullet$ C / EBP • IL6-DBP
\end{abstract}

\section{Introduction}

During the development of higher eukaryotes, certain genes become activated in a cell-type-specific manner. This tissuespecific gene activation is controlled by transcription factors that are, themselves, enriched in particular cell types such as the hepatocyte. For example, the albumin gene is specifically expressed in the liver after birth, and this expression is regulated predominantly at the level of transcription $(1,2)$.

We have reported the isolation of a cDNA clone encoding a

Portions of this work were presented at the meeting on Regulation of Liver Gene Expression in Health and Disease, Cold Spring Harbor Laboratory, Cold Spring Harbor, NY, 5-9 May 1993.

Address correspondence to Mario Chojkier, Department of Medicine and Center for Molecular Genetics (9111-D), University of California, San Diego, San Diego, CA 92161. Dr. Trautwein's current address is Department of Medicine, Medizinische Hochschule Hannover, Hannover, Germany.

Received for publication 1 November 1993 and in revised form 11 February 1994.

The Journal of Clinical Investigation, Inc.

Volume 93, June 1994, 2554-2561 liver-activator protein, LAP, a major albumin promoter D-site binding protein that confers liver-specific gene expression (3). LAP, a member of the C/EBP family (4), has also been named NF-IL6 (5), IL6-DBP (6), AGP/EBP (7), C/EBP $\beta$ (8), and CRP2 (9). LAP stimulates the transcription of chimeric genes containing albumin promoter D-elements both in vivo and in vitro $(3,6)$. LAP shares extensive sequence homology $(71 \%)$ in its DNA-binding and leucine zipper domains with $\mathrm{C} / \mathrm{EBP} \alpha$, and these proteins show indistinguishable DNA-binding specificity and readily heterodimerize $(3,9)$. Another product of the LAP gene has been identified, LIP (liver-inhibitory protein), which consists of the 152 amino acids of the $\mathrm{COOH}$ terminus of LAP. LIP can be translated from LAP mRNA and it behaves as an antagonist of LAP-induced transcription from the albumin promoter (10).

In response to environmental signals, modulation of target gene expression can be achieved through posttranslational modifications of transcriptional activators (11). For example, phosphorylation and dephosphorylation of nuclear proteins have been shown to be crucial to the ability of these proteins to bind to cognate DNA sequences, activate gene transcription, and/or affect progression through the cell cycle (12-14). Likewise, activation of signal transduction pathways may result in the phosphorylation of LAP and regulation of its activity as suggested previously ( 3 ). In this connection, it has been shown that activation of the cAMP-dependent protein kinase $\mathrm{A}$ (PKA) ${ }^{1}$ in rat pheochromocytoma PC1 2 cells causes increased phosphorylation and nuclear translocation of LAP and concomitant induction of c-fos transcription (15). In pituitary $\mathrm{G} / \mathrm{C}$ cells, calcium-regulated phosphorylation of $\operatorname{Ser}^{276}$ within the leucine zipper domain of LAP stimulates transcription from a $\mathrm{Ca}^{2+}$-calmodulin-dependent protein kinase II-responsive element (13). We have recently shown that phosphorylation of LAP at Ser ${ }^{105}$ is stimulated upon activation of protein kinase $\mathrm{C}$ (PKC) by treatment of HepG2 cells with phorbol esters, and that this phosphorylation enhances LAP transactivation activity (16).

Prompted by these reports of LAP phosphorylation in intact cells, we have studied the ability of PKA and PKC to phosphorylate LAP in vitro and have tested the effect of phosphorylation by PKA and PKC on the ability of LAP to recognize its cognate DNA elements. We show that $\operatorname{Ser}^{105}$ is a major phosphoacceptor for PKA in vitro, but that this posttranslational modification of LAP does not affect its binding affinity for its cognate response element in target genes. PKA-mediated phosphorylation of other sites, identified in the region between $\operatorname{Ser}^{173}$ and $\mathrm{Ser}^{223}$ and of $\mathrm{Ser}^{240}$, resulted in an inhibition of DNA binding. We identified the main in vitro phos-

1. Abbreviations used in this paper: PKA, protein kinase A; PKC, protein kinase $\mathrm{C}$; wt, wild type. 
phorylation site for PKC as $\operatorname{Ser}^{240}$ within the DNA-binding domain of LAP. Phosphorylation at this site markedly impaired the binding of LAP to its DNA recognition element.

\section{Methods}

Plasmid construction and site-directed mutagenesis. The full-length cDNA of LAP subcloned in pBS (Stratagene Inc., La Jolla, CA ) was cut with SphI/EcoRI and religated to obtain pBS-LAP ${ }_{\Delta 21}$. LAP $_{\Delta 21}$ corresponds to the major form of LAP expressed in the liver ( 3 ), because of the preferential translation from the second AUG of LAP mRNA (10). Deletion of the first 21 amino acids has no effect on the function of LAP as a trans-acting factor or on its binding to DNA. In this manuscript, LAP $_{\Delta 21}$ is referred to as LAP, as reported previously (3). For site-directed mutagenesis, the cDNA of pBS LAP L21 $_{\Delta a s}$ used to prepare single-stranded DNA in the Escherichia coli strain JM 109 using the helper phage M13 KO 7, according to Sambrook et al. (17). Sitedirected mutagenesis was performed by using the mutagenesis kit available from Amersham Corp. (Arlington Heights, IL) according to the supplier's instructions. The following oligonucleotides served as primers: Ala ${ }^{105}$ mutation, 5'-TA ACC GTA GTC GGC CGG CTT CTT GCT C-3'; Asp ${ }^{105}$ mutation, 5'-TA ACC GTA GTC ATC CGG CTT CTT GCT C-3'; Ala ${ }^{240}$ mutation, 5'-CCG CTT GTC GCG AGC CTT GCG CAC CGC-3'; Asp $^{240}$ mutation, 5'-CCG CTT GTC GCG GTC CTT GCG CAC CGC-3'.

The resulting mutants were sequenced, and fragments containing the correct mutations were introduced into the $\mathrm{LAP}_{\Delta 21} \mathrm{cDNA}$. For expression in mammalian cells the wild type (wt) and mutant LAP cDNAs were subcloned into cytomegalovirus-driven expression vectors. These same constructs were also inserted into bacterial expression vectors, transformed into the $E$. coli strain BL $21 / \mathrm{DE}-3 /$ pLys S (18), and purified as described previously $(3,19)$. A smaller segment of LAP was removed from the LAP clone encoding amino acids 187 to 297 and inserted into the vectors described above, for the expression of LAP SMA $_{\text {. }}$

Phosphorylation of $L A P$ in vitro by $P K A$. For PKA phosphorylation reactions, $3 \mu \mathrm{g}$ of either recombinant purified LAP or myosin light chain (Sigma Chemical Co., St. Louis, MO) was assayed in the presence of the following (mM): $10 \mathrm{MgCl}_{2}, 202-(N$-morpholino)ethanesulfonic acid (MES), 2 EGTA, 1 EDTA, and $100 \mu \mathrm{M}$ ATP, containing $20 \mu \mathrm{Ci}$ of $\left[\gamma^{32} \mathrm{P}\right]$ ATP $(3,000 \mathrm{Ci} / \mathrm{mmol}$; Amersham Corp.) (final sp act $5,000 \mathrm{dpm} / \mathrm{pmol})$. Reactions were initiated by the addition of $2 \mu \mathrm{l}$ of purified PKA catalytic subunit $(5 \mathrm{mg} / \mathrm{ml} ; 21 \mathrm{U} / \mathrm{mg}$ ) (kindly provided by Dr. Susan Taylor, University of California, San Diego), and carried out for $20 \mathrm{~min}$ at $30^{\circ} \mathrm{C}$. Proteins were precipitated on ice with $2.5 \mathrm{vol}$ of $100 \%$ ethanol after the addition of $5 \mu \mathrm{g}$ serum albumin as a carrier. Phosphorylation was assessed by autoradiography after SDS-gel electrophoresis on a $10 \%$ polyacrylamide gel (20).

Phosphorylation of LAP in vitro by $P K C$. For PKC reactions, $3 \mu \mathrm{g}$ of recombinant purified LAP $(20 \mathrm{ng} / 36 \mu \mathrm{l})$ was assayed at $30^{\circ} \mathrm{C}$ in the presence of $200 \mu \mathrm{g} / \mathrm{ml}$ freshly sonicated phosphatidylserine (Sigma Chemical Co.), $70 \mathrm{mM}$ Tris- $\mathrm{HCl}$ (pH 7.5), $0.1 \mathrm{mM} \mathrm{CaCl}, 7 \mathrm{mM}$ $\mathrm{MgCl}_{2}, 5 \mu \mathrm{g}$ serum albumin, and $1 \mu \mathrm{l}$ of purified bovine brain PKC ( $100 \mathrm{ng} / \mathrm{ml}$ ) containing a mixture of the $\alpha, \beta$, and $\gamma$ isoforms (21) (kindly provided by Dr. Gordon Gill, University of California, San Diego). The reaction was initiated by the addition of $100 \mu \mathrm{M}$ [ $\left.\gamma^{32} \mathrm{P}\right]$ ATP $(5,000 \mathrm{dpm} / \mathrm{pmol})$. For phosphatase treatment, $2 \mathrm{U}$ of potato acid phosphatase (Boehringer Mannheim Corp., Indianapolis, IN) was added to the kinase reaction at $30^{\circ} \mathrm{C}$ for $15 \mathrm{~min}$. The phosphatase reaction was stopped by placing the samples at $4^{\circ} \mathrm{C}$, and the reactions were terminated by adding an equal volume of $4 \times$ Laemmli sample buffer. Proteins were resolved on a $10 \%$ SDS-polyacrylamide gel.

Tryptic phosphopeptide mapping, phosphoamino acid analysis, and manual Edman degradation. For tryptic mapping, proteins were blotted onto a nitrocellulose membrane (Schleicher and Schuell, Keene, $\mathrm{NH}$ ) in $1 \%$ SDS, $20 \%$ methanol, $400 \mathrm{mM}$ glycine, $50 \mathrm{mM}$ Tris- $\mathrm{HCl}$,
$\mathrm{pH} 8.3$, for $2 \mathrm{~h}$ at $200 \mathrm{~mA}$. Proteins were visualized by autoradiography of the wet filter. The LAP band was excised and then washed twice with freshly made $0.05 \mathrm{M} \mathrm{NH}_{4} \mathrm{HCO}_{3}$. The immobilized LAP protein was digested with $10 \mu \mathrm{g}$ TPCK-trypsin (Worthington Biochemical Corp., Freehold, $\mathrm{NJ}$ ) by incubation for $4 \mathrm{~h}$ at $37^{\circ} \mathrm{C}$ in $150 \mathrm{ml} \mathrm{NH}_{4} \mathrm{HCO}_{3} .10$ $\mu \mathrm{g}$ of fresh enzyme was then added for a further 3-h incubation.

After the digestion samples were centrifuged for $10 \mathrm{~min}$ at $14,000 \mathrm{~g}$, the supernatants were transferred to fresh tubes and lyophilized. The pellet was oxidized in $50 \mu \mathrm{l}$ performic acid for $60 \mathrm{~min}$ on ice. Immediately after the incubation $400 \mu \mathrm{l}$ of water was added, the sample was frozen on dry ice and lyophilized. The sample was dissolved in pH 1.9 buffer and spotted on a $100-\mu \mathrm{m}$ cellulose TLC plate. Phosphopeptides were separated in the first dimension by electrophoresis at $\mathrm{pH} 1.9$ at 1 $\mathrm{kV}$ for $30 \mathrm{~min}$ (22). Separation in the second dimension was done by chromatography in phosphochromatography buffer (22).

For phosphoamino acid analysis the tryptic digest was dissolved in $50 \mu \mathrm{l} 6 \mathrm{~N} \mathrm{HCl}$ and incubated for $1 \mathrm{~h}$ at $110^{\circ} \mathrm{C}$, lyophilized, and dissolved in $5 \mathrm{ml}$ of pH 1.9 buffer. The samples were mixed with $1 \mu \mathrm{g}$ of the unlabeled phosphoamino acids phosphoserine, phosphothreonine, and phosphotyrosine, and spotted on a $100-\mu \mathrm{m}$ cellulose TLC plate. Samples were separated by electrophoresis for $20 \mathrm{~min}$ at $2 \mathrm{kV}$ in the first dimension at pH 1.9 and for $20 \mathrm{~min}$ at $2 \mathrm{kV}$ at pH 3.5 buffer $(5 \%$ glacial acetic acid, $0.5 \%$ pyridine in water) in the second dimension. The unlabeled phosphoamino acids markers were visualized by ninhydrin staining, and ${ }^{32} \mathrm{P}$-labeled phosphoamino acids were detected by autoradiography.

Edman degradation was performed exactly as described by Boyle et al. (22). The samples from each cycle were spotted $1 \mathrm{~cm}$ apart on a $100-\mu \mathrm{m}$ cellulose TLC plate and electrophoresed in $\mathrm{pH} 1.9$ buffer for $25 \mathrm{~min}$ at $1 \mathrm{kV}$.

Gel retardation assays. For the gel retardation assays $1 \mathrm{ng}$ of recombinant bacterially expressed LAP was used. An oligonucleotide (5'TGGTATGATTTTGTAATGGGG-3') spanning the D-site of the albumin promoter ( $1 \mathrm{ng}$ ) was used as a probe. Free DNA and DNA-protein complexes were resolved on a $6 \%$ polyacrylamide gel as described previously (3).

\section{Results}

In vitro phosphorylation of LAP at $\operatorname{Ser}^{105}$ by PKA. As we reported previously (3), analysis of the amino acid sequence of LAP revealed possible phosphoacceptor sites for PKA-mediated phosphorylation in the $\mathrm{NH}_{2}$ terminus of LAP. Therefore we investigated whether LAP could be a substrate of phosphorylation by PKA in vitro. Purified bacterially expressed LAP was phosphorylated by PKA and the products were separated by SDS-PAGE. Fig. $1 A$ shows that phosphorylation of LAP occurred in the presence (lane 2) but not in the absence (lane 1) of PKA catalytic subunit. Myosin light chain was used as a positive control for PKA phosphorylation (lane 3). Minor phosphorylation products (lanes 2 and 3 ) could be due to contaminating proteins in the PKA preparation or in the LAP preparation.

Next, we set out to identify the site(s) phosphorylated in LAP by PKA. Phosphoamino acid analysis showed that LAP was phosphorylated mainly on serine by PKA although a low level of threonine phosphorylation was also detected (Fig. 1 $B)$. As a next step, phosphopeptides resulting from a tryptic digest of phosphorylated LAP were resolved by electrophoresis and chromatography in two dimensions on cellulose TLC plates. Several peptides were found to be phosphorylated (Fig. $2 A$ ). The arrowhead indicates the main PKA phosphopeptide (spot I). $53 \%$ of the $\left[{ }^{32} \mathrm{P}\right]$ phosphate incorporated into LAP by PKA phosphorylation was present in spot I, with the rest of the 
A

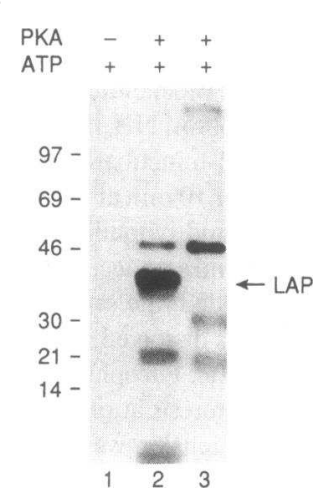

Figure 1. Phosphorylation of LAP by PKA in vitro. $(A)$ Recombinant LAP was phosphorylated by PKA in vitro as described in Methods. The reaction was performed in the absence (lane 1) or in the presence (lane 2) of PKA and $\left[\gamma-{ }^{32} \mathrm{P}\right]$ ATP. The arrow indicates LAP with an apparent molecular mass of $36 \mathrm{kD}$ as reported previously $(3,10)$. As a control myosin light chain was phosphorylated by PKA (lane 3 ). (B) Phosphoamino acid analysis of LAP after phosphorylation by PKA in vitro. Phosphorylated LAP was hydrolyzed in $6 \mathrm{~N} \mathrm{HCl}$, and phosphoamino acids were separated by two-dimensional electrophoresis on TLC plates. The arrowhead indicates the migration of the phosphoserine standard. A trace of phosphothreonine is evident just to the right of the phosphoserine. The origin is in the right lower corner.

radioactivity being contained in several other phosphopeptides. A computer-assisted prediction of the mobilities of LAP tryptic peptides during separation on thin layer cellulose plates indicated that the peptide containing $\operatorname{Ser}^{105}$ is the most likely candidate for spot I (KPS ${ }^{105}$ DYGYVSLGR). In this tryptic peptide $\mathrm{Ser}^{105}$ is three amino acids away from the $\mathrm{NH}_{2}$ terminus. This prediction was confirmed using manual Edman degradation during which free $\left[{ }^{32} \mathrm{P}\right]$ phosphate was released after the third cycle.

As a more definitive proof of the identification of this phosphorylation site, the serine codon at position 105 was mutated to an alanine codon, thus introducing a residue that cannot be phosphorylated. Fig. $2 B$ shows that PKA-phosphorylated LAP $\mathrm{Ala}^{105}$ lacks spot I, as expected if this peptide contains P. Ser ${ }^{105}$. Similar results were obtained when $\operatorname{Ser}^{105}$ was mutated to Asp $^{105}$ (not shown). These results confirm that $\operatorname{Ser}^{105}$ is the main site of LAP phosphorylated by PKA in vitro.

Phosphorylation of $L A P$ by PKA changes the binding to the albumin promoter D-site. Because $\mathrm{Ser}^{105}$ is the main PKA phosphorylation site of LAP in vitro and because our previous analysis of LAP phosphorylated in vivo also showed strong phosphorylation at $\operatorname{Ser}^{105}(16)$, we investigated whether phosphorylation of LAP by PKA has any effect on the binding of LAP to the D-site of the albumin promoter. This analysis is potentially complicated by the fact that in addition to $\operatorname{Ser}^{105}$, other serines in LAP are phosphorylated by PKA in vitro, and these phosphorylations might also affect binding to the D-site.

To analyze the effect of in vitro phosphorylation of these different sites on LAP DNA binding, we phosphorylated both wt LAP and a truncated form of LAP lacking Ser ${ }^{105}$ ( LAP $_{\text {SMA }}$; amino acids 187-297) with PKA and performed gel shift studies. A small decrease of $\sim 30 \%$ in the DNA-binding affinity of wt LAP was observed after phosphorylation (Fig. $3 A$ ), initially suggesting that phosphorylation of Ser ${ }^{105}$ inhibited DNA bind-
A

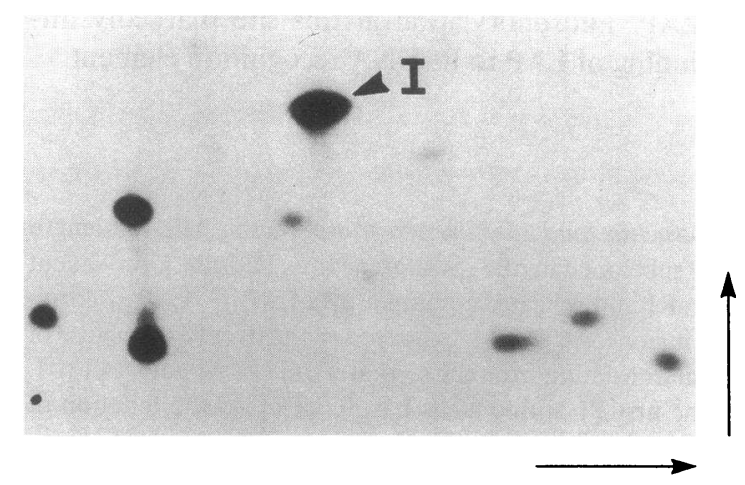

B

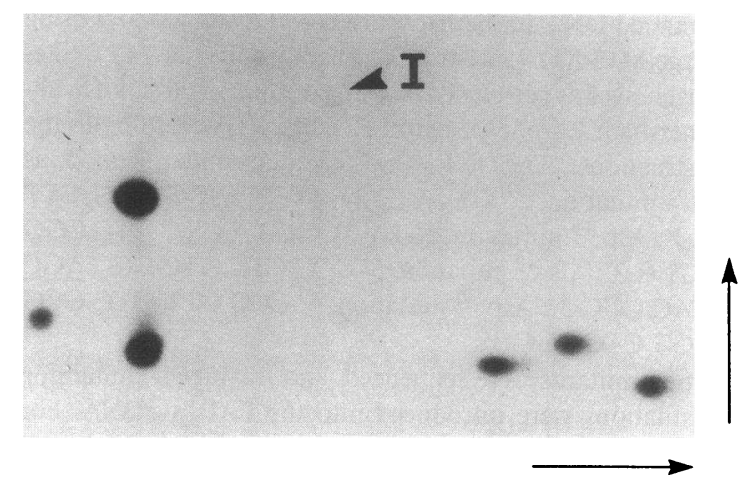

Figure 2. The main PKA phosphorylation site of LAP is $\operatorname{Ser}^{105}$. (A) Tryptic map of ${ }^{32} \mathrm{P}$-labeled wt LAP. LAP was phosphorylated in the presence of PKA and $\left[\gamma^{-32} \mathrm{P}\right] \mathrm{ATP}$ and separated by SDS-PAGE as shown in Fig. $1 A$. After transfer onto nitrocellulose, tryptic peptide mapping was performed as described in Methods. The resultant peptides were separated on cellulose TLC plates by high voltage electrophoresis at pH 1.9 (horizontal dimension) followed by ascending chromatography (vertical dimension). The origin is in the left lower corner and the cathode was on the right. The main peptide, spot I, is indicated with an arrowhead. $(B)$ Tryptic map of ${ }^{32} \mathrm{P}$-labeled mutant LAP Ala ${ }^{105}$. LAP Ala ${ }^{105}$ was phosphorylated and processed as described under $A$.

ing. However, since phosphorylation of the truncated LAP $_{\text {SMA }}$, which lacks Ser ${ }^{105}$, decreased DNA binding by $65 \%$ (Fig. $3 B$, lanes 1 and 2), it appeared that the inhibitory effect of PKA phosphorylation on wt LAP DNA binding was due to phosphorylation of sites other than $\mathrm{Ser}^{105}$. From other experiments with various truncated forms of LAP described by Wegner et al. (13), we localized the additional PKA phosphorylation sites to a region just upstream of the DNA-binding domain between $\mathrm{Ser}^{173}$ and $\mathrm{Ser}^{223}$ (not shown), and to $\mathrm{Ser}^{240}$ within the DNA-binding domain. To prove that phosphorylation at sites other than Ser ${ }^{105}$ inhibited DNA binding, we investigated the effect of PKA phosphorylation of the LAP Ala ${ }^{105}$ mutant. A dramatic $\sim 80 \%$ decrease in binding to the D-site oligonucleotide resulted from the phosphorylation of mutant LAP Ala ${ }^{105}$ by PKA (Fig. $3 C$ ). Similar results were obtained after phosphorylation of mutant LAP Asp ${ }^{105}$ by PKA (not shown). We conclude that the inhibitory effects of PKA phosphorylation on DNA binding are due to phosphorylation of sites located close to or in the DNA-binding domain that are common to wt LAP, LAP ${ }_{\text {SMA }}$, LAP Ala ${ }^{105}$, and LAP Asp ${ }^{105}$. The smaller inhibitory effect on wt LAP DNA binding could be explained if 
A

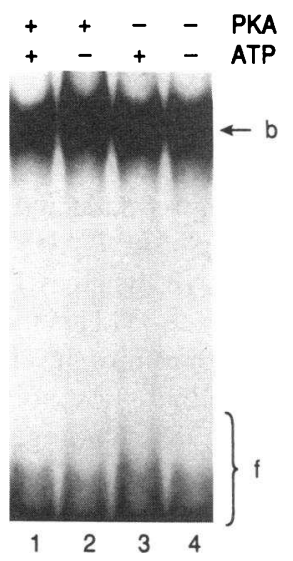

B

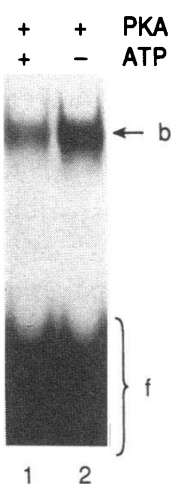

\section{C}

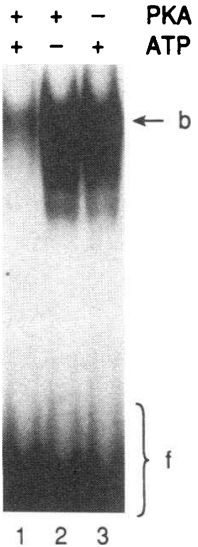

Figure 3. PKA phosphorylation of LAP modulates its affinity to the albumin D-site. $(A)$ wt LAP was incubated with $(+)$ and without $(-)$ PKA at $30^{\circ} \mathrm{C}$ in the presence $(+)$ or absence $(-)$ of ATP as indicated. $1 \mathrm{ng}$ of each reaction was incubated with a ${ }^{32} \mathrm{P}$-labeled site $\mathrm{D}$ oligonucleotide and processed as indicated in Methods. The DNA-protein complexes were resolved on a $6 \%$ nondenaturing polyacrylamide gel. The positions of free $(f)$ and bound $(b)$ DNA are indicated. $(B)$ LAP $_{\text {SMA }}$ (amino acids 189-297) was incubated with PKA at $30^{\circ} \mathrm{C}$ in the presence or absence of ATP as indicated in Methods. $1 \mathrm{ng}$ of $\mathrm{LAP}_{\mathrm{SMA}}$ was incubated with a ${ }^{32} \mathrm{P}$-labeled site $\mathrm{D}$ oligonucleotide and processed as indicated in Methods. $(C) \mathrm{Mu}$ tant LAP Ala ${ }^{105}$ was incubated with (+) and without (-) PKA or ATP at $30^{\circ} \mathrm{C} .1 \mathrm{ng}$ of protein was incubated with the ${ }^{32} \mathrm{P}$-labeled site $\mathrm{D}$ oligonucleotide and processed as indicated in Methods. the absence of the main $\operatorname{Ser}^{105}$ phosphorylation site in all three mutant LAP proteins leads to stronger phosphorylation of the sites close to or in the DNA-binding domain. In addition, phosphorylation of wt LAP on Ser ${ }^{105}$ may induce a conformational change in LAP that masks the phosphorylation sites in the vicinity of the DNA-binding domain. As will be discussed below, phosphorylation of $\operatorname{Ser}^{240}$ by PKA is most likely responsible for the observed decrease in LAP DNA-binding activity.

As another way of showing that phosphorylation of Ser ${ }^{105}$ itself had no effect on DNA binding, a mutant LAP protein was expressed in which the serine at position 105 is replaced by an aspartate, which should mimic the effect of $\mathrm{Ser}^{105}$ phosphorylation by introducing a negative charge. DNA-binding curves were obtained for wt LAP and the LAP Ala ${ }^{105}$ and LAP Asp ${ }^{105}$ mutant proteins to monitor possible changes in binding due to the phosphorylation of $\operatorname{Ser}^{105}$. Fig. 4 shows that the DNA-binding affinities of the three different LAP forms to the oligo D-site are very similar. These results confirm that the decrease in DNA binding of the LAP protein after PKA phosphorylation is related to the phosphorylation site(s) close to the DNA-binding domain and that phosphorylation of $\mathrm{Ser}^{105}$ itself has no effect on DNA binding.

In vitro phosphorylation of $L A P$ by $P K C$. In a recent study, Li et al. (23) showed that PKC phosphorylates a threonine residue in the DNA-binding domain of myogenin, which in turn blocks DNA binding. Several likely phosphoacceptor sites for PKC phosphorylation are present in the DNA-binding domain of LAP. Therefore, we investigated whether LAP could be phosphorylated in its DNA-binding domain by PKC. The tryptic map of LAP phosphorylated by PKC (Fig. $5 A$ ) shows a pattern related to that found for LAP phosphorylated by PKA (compared to Fig. $2 A$ ). However, the intensity of three basic phosphopeptides (spots II) is much greater relative to spot I than with PKA. To obtain more information about these three spots, we performed Edman degradation on these three phosphopeptides. The three spots showed release of free phosphate either after the first or the second cycle of Edman degradation. This analysis identified $\operatorname{Ser}^{223}$ and $\mathrm{Ser}^{240}$ as good candidate acceptor sites for phosphorylation by PKC. The relative mobilities of the three spots suggested that they might be derived by incomplete trypsin digestion of a single phosphorylation site. Specifically, $\operatorname{Ser}^{240}$ was a likely candidate because the Arg and Lys around $\operatorname{Ser}^{240}$ occur in pairs (see Fig. 5), which is known to result in partial tryptic digests (22).
We noted that one of the predicted phosphopeptides generated by trypsin digestion of the sequence around $\operatorname{Ser}^{240}$ in LAP would be the same as that generated by digestion of the sequence containing the main PKC phosphorylation site in the cytoplasmic tail of the $\alpha$ subunit of the IL2-receptor (Fig. $5 \mathrm{~B}$ ). Therefore, a synthetic IL2 receptor peptide described by Woodgett et al. (24) was phosphorylated by PKC, digested with trypsin and the peptides were separated in two dimensions. The tryptic map (Fig. $5 C$ ) showed the more basic of the IL2 receptor-derived phosphopeptides comigrated with the middle peptide of the spots II cluster (Fig. $5 A$ ). On the basis of this information and their relative mobilities, we tentatively identify the most acidic spot in this cluster as P.Ser ${ }^{240}$-Arg-AspLys, the central spot as P.Ser ${ }^{240}$-Arg, and the most basic spot as Lys-P.Ser ${ }^{240}$-Arg-Asp-Lys.

From these experiments we concluded that $\operatorname{Ser}^{240}$ is the main PKC phosphorylation site. Therefore, the serine codon at position 240 was mutated to an alanine codon, and recombinant-LAP $\mathrm{Ala}^{240}$ was phosphorylated by PKC in vitro. The tryptic map of LAP $\mathrm{Ala}^{240}$ showed the disappearance of the three main PKC phosphopeptide spots (Fig. $5 \mathrm{D}$ ), indicating that all three are related to each other and confirming that $\mathrm{Ser}^{240}$ is the main PKC phosphorylation site in LAP.

Phosphorylation of LAP at Ser ${ }^{240}$ blocks the binding to the albumin promoter $D$-site. The main PKC phosphorylation site of LAP is $\mathrm{Ser}^{240}$. This site is located in the basic region of the DNA-binding domain of LAP and a likely candidate for the decrease in DNA binding seen with the $\mathrm{LAP}_{\mathrm{SMA}}$ protein and the LAP mutants at position 105 after PKA phosphorylation. As $\sim 90 \%$ of the phosphate was incorporated at $\operatorname{Ser}^{240}$ due to PKC phosphorylation, we determined the percentage of P.Ser ${ }^{240}$ after phosphorylation of LAP by PKC. Stoichiometric analysis showed that $>50 \%$ of LAP molecules were phosphorylated at $\operatorname{Ser}^{240}$ (data not shown).

To test whether PKC phosphorylation affected the binding of LAP to DNA, we performed gel shift experiments with PKCphosphorylated LAP and a ${ }^{32} \mathrm{P}$-labeled oligonucleotide spanning the albumin promoter D-site. The binding of LAP to the cognate DNA was nearly completely abolished by PKC phosphorylation (Fig. $6 \mathrm{~A}$, lane 1 ), when compared with control incubations with ATP or PKC alone (Fig. $6 A$, lanes 3 and 4 ). The decrease in binding was partially reversed by potato acid phosphatase treatment after the phosphorylation of LAP by PKC (Fig. $6 A$, lane 2 ). The failure to obtain complete reversal 


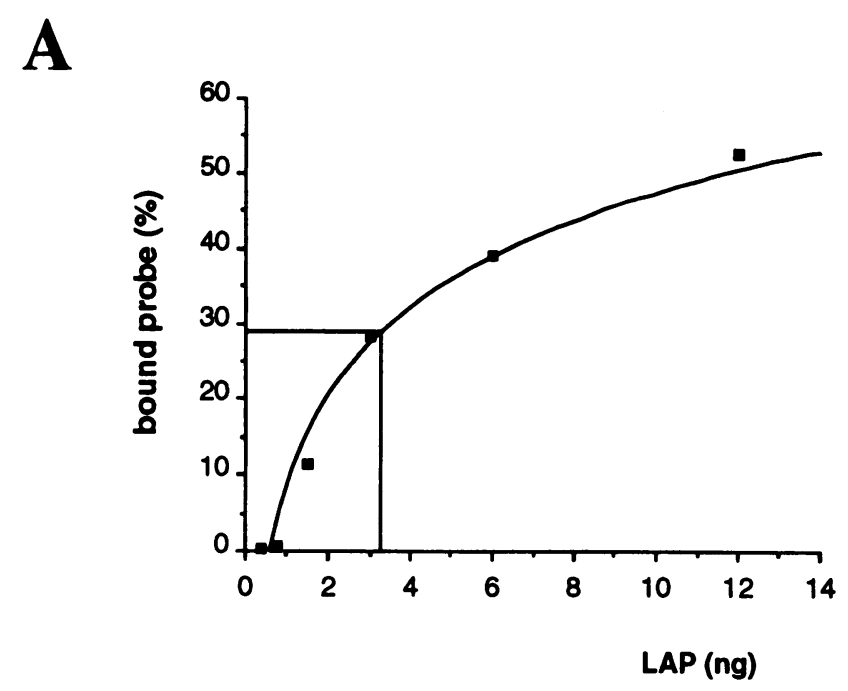

B

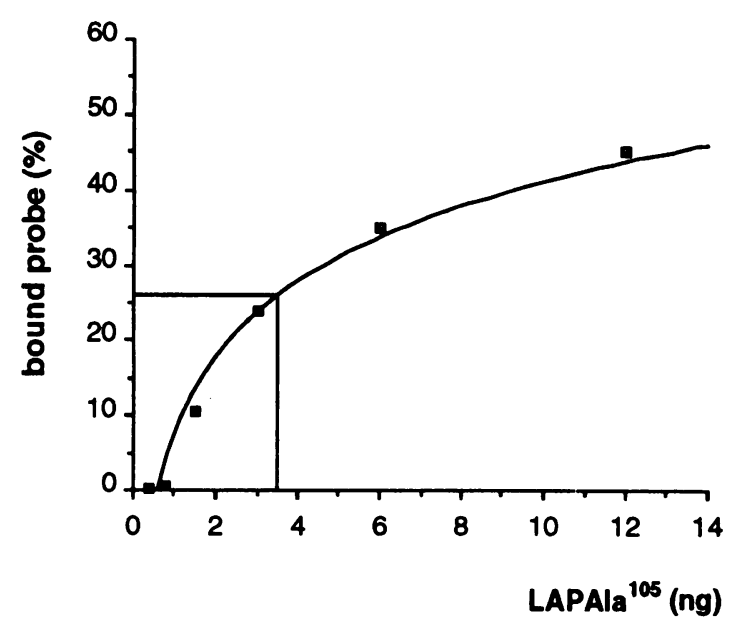

C

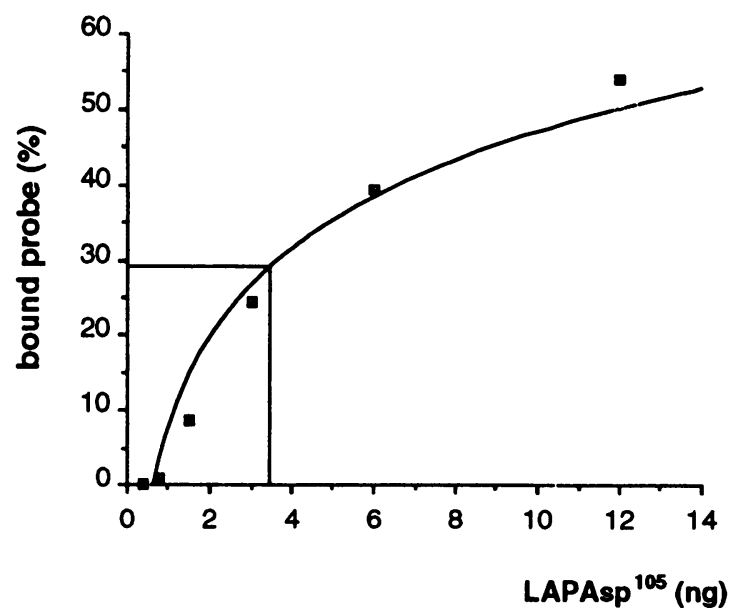

Figure 4. DNA binding affinity of wt LAP, LAP Ala ${ }^{105}$, and LAP Asp ${ }^{105} .{ }^{32} \mathrm{P}$-labeled oligo-D ( $\left.15 \mathrm{pg}\right)$ was incubated with an increasing amount of recombinant wt LAP $(A), \operatorname{LAP} \operatorname{Ala}^{105}(B)$, and $\operatorname{Asp}^{105}$ $(C)$. The DNA-protein complexes were resolved on a $6 \%$ nondenaturing polyacrylamide gel. The fraction of the probe specifically bound was quantified (percent specific shifted probe) by phosphoimaging and plotted as a function of the amount of recombinant protein. The percentage of specific occupancy is indicated. was probably due to the continued presence in the incubation of ATP, which acts as a competitive inhibitor of the phosphatase. Treatment with phosphatase had no effect on the phosphorylation of the oligonucleotide (Fig. 6).

To test whether the inhibition of DNA binding detected after phosphorylation of LAP at $\mathrm{Ser}^{240}$ can be mimicked by the introduction of an aspartate at this position, we made and expressed an LAP Asp ${ }^{240}$ mutant. The binding of LAP Ala ${ }^{240}$ to the D-site was comparable to that of wt LAP, whereas LAP Asp ${ }^{240}$ did not bind to the D-site, (Fig. $6 \mathrm{~B}$, lane 3 ). This shows that the presence of aspartate at position 240 mimics the effect of phosphorylation of $\operatorname{Ser}^{240}$ and establishes that phosphorylation of $\operatorname{Ser}^{240}$ by PKC is sufficient to block DNA binding.

\section{Discussion}

In this report, we show that site-specific phosphorylation of LAP can modulate its affinity for the D-site of the albumin promoter. We started by investigating whether PKA could phosphorylate LAP in vitro, because of a prior report that LAP is phosphorylated in PC12 cells after induction of CAMP pathways. In that study it was not determined whether PKA phosphorylates LAP directly, and the LAP phosphoacceptor site(s) were not identified (15). Here we demonstrate that purified recombinant LAP can be phosphorylated in vitro by the catalytic subunit of PKA. Using a combination of phosphoamino acid analysis, phosphopeptide mapping, and Edman degradation, we identified the major PKA phosphorylation site as $\operatorname{Ser}^{105}$ (Fig. 7), which is part of a characteristic phosphoacceptor sequence (SKKPS ${ }^{105}$ ) for PKA (consensus R/K R/K X $S / T)(3)$. We confirmed our identification by showing that this PKA phosphorylation site disappears after its mutation (Ser ${ }^{105}$ to Ala, or Ser ${ }^{105}$ to Asp). Wegner et al. (13) were able to phosphorylate recombinant mouse LAP in vitro with $\mathrm{Ca}^{2+}$ calmodulin-dependent kinase II at $\operatorname{Ser}^{276}$ (Fig. 7), but they reported only weak phosphorylation with the PKA catalytic subunit. The apparent discrepancy between these results can be reconciled, since the recombinant LAP protein used by Wegner and co-workers (13) was derived from a mouse LAP cDNA clone that lacks the corresponding serine, having alanine instead in the corresponding position (8), which cannot be phosphorylated. Both rat and human LAPs contain Ser ${ }^{105}$ $(3,6,9)$. The significance of this difference between the mouse LAP sequence and the other vertebrate LAP sequences is unclear.

Our results indicate that phosphorylation of $\operatorname{Ser}^{105}$ does not alter the binding of LAP to the cognate albumin promoter Dsite. In particular, we found that recombinant LAP Asp ${ }^{105} \mathrm{mu}$ tant protein in which the Asp mimics P.Ser ${ }^{105}$, displayed unchanged DNA-binding affinity. Moreover, although phosphorylation of wt LAP by PKA decreased DNA-binding activity of LAP, the same was true for the Ala ${ }^{105}$ mutant LAP protein. This indicates that PKA phosphorylation of sites other than Ser ${ }^{105}$ in LAP results in decreased binding affinity for the albumin promoter D-site. These additional PKA phosphorylation sites were mapped to the region between $\operatorname{Ser}^{175}$ and $\operatorname{Ser}^{223}$ in close proximity to the DNA-binding domain and to $\operatorname{Ser}^{240}$. Based on results obtained with PKC, it seems likely that PKAdependent phosphorylation of $\operatorname{Ser}^{240}$ is responsible for the decreased DNA binding. 

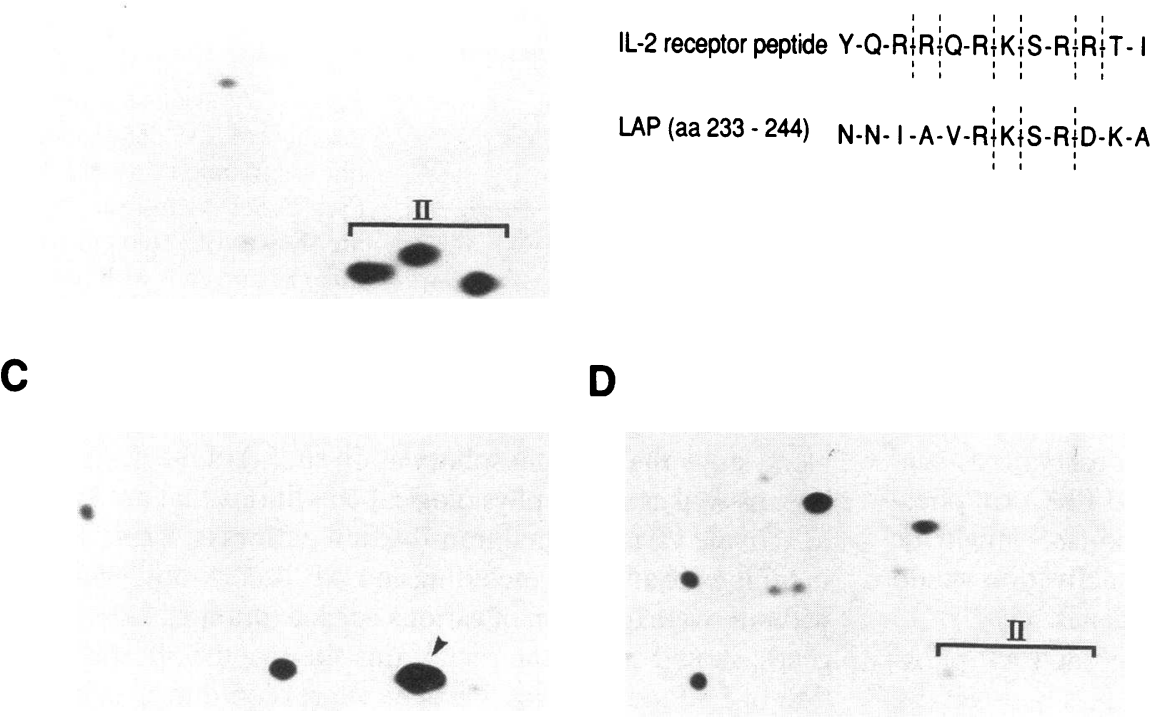

Figure 5. The main PKC phosphorylation site of LAP is $\operatorname{Ser}^{240}$. ( $A$ ) Recombinant LAP was phosphorylated by PKC in vitro as described in Methods. Phosphorylation products were separated on a $10 \%$ SDS-gel and blotted onto a nitrocellulose membrane. Tryptic mapping was performed as described in Methods. The main phosphopeptides are indicated as spots II. ( $B)$ Sequence comparison between the synthetic

\section{D}

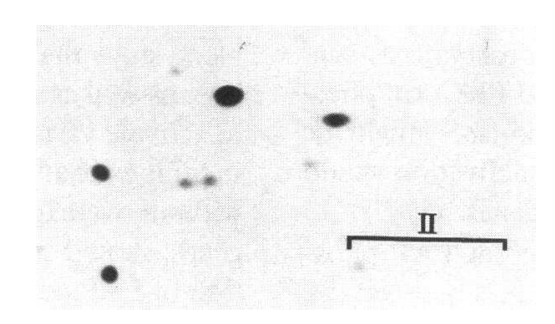

IL-2 receptor peptide and LAP at amino acids 232-247. The possible trypsin cleavage sites are indicated. $(C)$ The synthetic IL-2 receptor peptide was phosphorylated by PKC, and tryptic mapping was performed as described in Methods. $(D) \mathrm{Mu}$ tant LAP Ala ${ }^{240}$ was phosphorylated by $\mathrm{PKC}$ in vitro. Identification and tryptic mapping of phosphorylated LAP was performed as described in Methods.
The major phosphoacceptor for PKC in vitro was mapped to $\mathrm{Ser}^{240}$ within the DNA-binding domain of LAP (Fig. 7). Phosphorylation of $\mathrm{Ser}^{240}$ or introduction of an $\mathrm{Asp}^{240}$ mutation, which mimics P.Ser ${ }^{240}$, resulted in marked reduction in

A
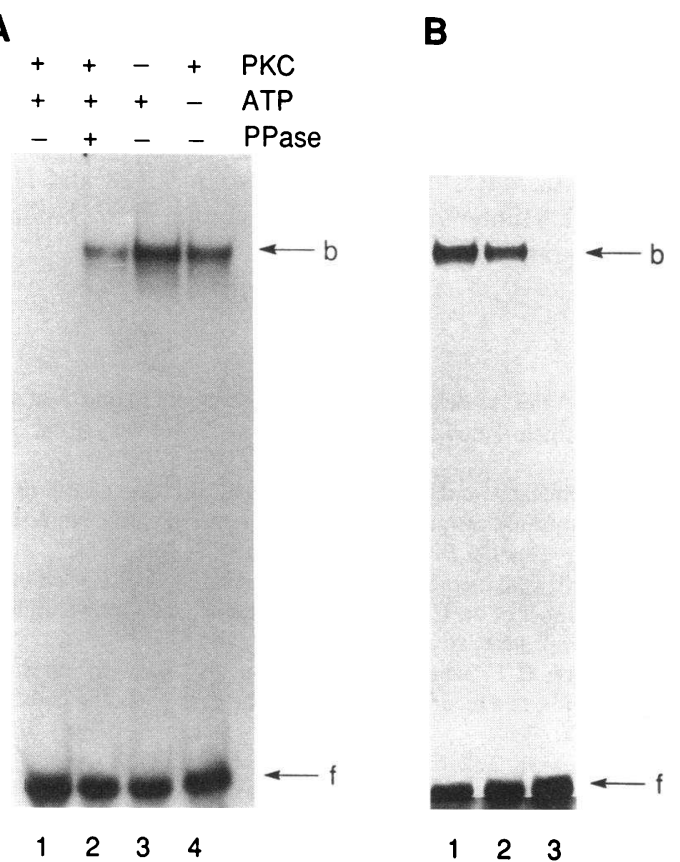

Figure 6. PKC phosphorylation of LAP inhibits its binding to the albumin D-site. $(A)$ wt LAP was incubated with $(+)$ and without $(-)$ PKC in the presence $(+)$ or absence $(-)$ of ATP at $30^{\circ} \mathrm{C}$. After PKC phosphorylation, the sample in lane 2 was additionally incubated with phosphatase for $15 \mathrm{~min}$ at $30^{\circ} \mathrm{C}$. After PKC phosphorylation and phosphatase treatment, $1 \mathrm{ng}$ of each sample was incubated with a ${ }^{32} \mathrm{P}$-labeled site-D oligonucleotide. The DNA-protein complexes were resolved on a $6 \%$ nondenaturing polyacrylamide gel. The positions of free $(f)$ and bound $(b)$ DNA are indicated. $(B) 1 \mathrm{ng}$ of wt LAP (lane 1), mutant LAP Ala ${ }^{240}$ (lane 2), or LAP Asp ${ }^{240}$ (lane 3) was incubated with a ${ }^{32} \mathrm{P}$-labeled site-D oligonucleotide. The DNAprotein complexes were resolved as indicated under $A$. the binding of LAP to its DNA recognition element. LIP, a liver-inhibitory protein (10), lacks the $\mathrm{NH}_{2}$ terminal domain of LAP, including the phosphoacceptor at $\mathrm{Ser}^{105}$, but it is susceptible to the other phosphorylations (Fig. 7). This differential phosphorylation may provide a mechanism for selective modulation of LAP activity, when compared with LIP activity.

Our previous study of LAP phosphorylation in HepG2 hepatoma cells identified $\mathrm{Ser}^{105}$ as a physiological phosphorylation site and showed that its phosphorylation was stimulated upon activation of PKC with concomitant enhancement of transcriptional activation (16). Since we have shown here that PKC does not phosphorylate $\mathrm{Ser}^{105}$ in vitro, this effect of PKC is likely to be indirect. In addition, a constitutively activated derivative of PKC that is predominantly nuclear (23) did not stimulate LAP activity or phosphorylation (our unpublished observations). Most probably, activation of cytoplasmic PKC results in activation of downstream protein kinases including one directly responsible for phosphorylation of LAP on Ser ${ }^{105}$. It also seems unlikely that PKA is responsible for phosphorylation of Ser ${ }^{105}$ in HepG2 cells, since in preliminary experiments we have found that treatment with forskolin to elevate the intracellular level of cAMP in HepG2 cells did not affect either the extent of LAP phosphorylation at $\mathrm{Ser}^{105}$ or its nuclear translocation (our unpublished observations). Likewise, other PKA activators or inhibitors did not lead to either higher or lower levels of LAP phosphorylation, respectively. In some ways this is surprising since activation of PKA leads to nuclear translocation of the $\mathrm{C}$ subunit. In contrast, in PC12 cells cAMP-induced phosphorylation of LAP is associated with its nuclear translocation (15). These results indicate that different mechanisms may be responsible for the phosphorylation of LAP in hepatoma and PC12 cells (15).

In our previous study, phosphorylation of $\operatorname{Ser}^{240}$ was not readily detected in intact HepG2 cells (16), but in subsequent experiments we have found that there is a low basal level of LAP phosphorylation at $\mathrm{Ser}^{240}$ in hepatoma cell lines. However, phosphorylation of $\mathrm{Ser}^{240}$ was not increased by activation of PKC or PKA in intact cells, even though both protein kinases can phosphorylate $\operatorname{Ser}^{240}$ in vitro (16, and our unpub- 


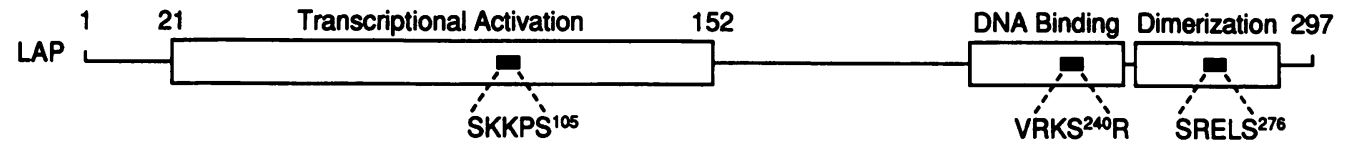
due 152 and ends with resi-

lished observations). Taken together these observations suggest that protein kinases other than PKA and PKC can phosphorylate LAP at $\mathrm{Ser}^{240}$ and such protein kinases might be regulated by other signaling pathways whose activation would result in decreased activation of LAP target genes.

What is the potential biological relevance of LAP phosphorylation in vivo? There are potential parallels between the regulation of LAP by phosphorylation, and the regulation of other leucine zipper transcription factors by phosphorylation. c-Jun, a member of the leucine zipper family, has five major phosphorylation sites, which are located near the DNA-binding domain and in the transactivation domain within the $\mathrm{NH}_{2}$ terminus (25-27). The affinity of c-Jun for AP-1 sites is decreased when it is phosphorylated in the region adjacent to the DNA-binding domain $(25,28)$. In contrast, c-Jun shows an increase in transcriptional activity after phosphorylation of two serines within its transactivation domain $(26,27)$. Phosphorylation also affects the activity of CREB. PKA phosphorylates CREB at $\operatorname{Ser}^{133}$ in vitro and in vivo $(29,30)$. Phosphorylation of CREB at. Ser ${ }^{133}$, which lies in the major transactivation domain, leads to a severalfold increase in transactivation from a chimeric reporter gene with a CREB-binding site without affecting DNA binding (29). Interestingly, this PKA-mediated phosphorylation of CREB plays a role in liver-specific gene regulation (31). The tyrosine aminotransferase (TAT) gene is regulated in a hepatocyte specific manner by CREB. PKA-mediated pathways stimulate transcription of the TAT gene by CREB in a rat hepatoma cell line FTO-2B (31).

Our experiments with the mutant LAP Asp ${ }^{105}$, which exhibits increased transactivation from an LAP-responsive DNA element, support the conclusion that phosphorylation of LAP in its transactivation domain stimulates transcription of specific target genes in vivo (16). This positive regulation is analogous to the stimulatory effect of phosphorylating the transactivation domain of other members of the leucine zipper family $(26,29)$. Conversely, LAP displays a decreased affinity for its cognate DNA-binding sites when phosphorylated in vitro in the DNA-binding domain or in its proximity by PKC or PKA, respectively. This resembles the inhibitory effect of phosphorylation of c-Jun in the vicinity of the basic domain, which is known to be physiologically relevant $(25,28)$. LAP is also potentially positively regulated by phosphorylation of $\mathrm{Ser}^{276}$ in the leucine zipper by calmodulin-dependent protein kinase II, which would be activated upon elevation of intracellular $\mathrm{Ca}^{2+}(13)$.

In this report we have identified and characterized the sitespecific phosphorylations of LAP critical for its interaction with cognate cis-elements in target genes. Now it will be possi- ble to study the LAP phosphorylation site(s) in the normal rat liver as well as under physiological conditions that are known to activate various signal transduction pathways. Experiments in transgenic animals, including an LAP "knock-out" with and without overexpression of various deleted/mutated LAP transgenes, should clarify the role of this site-specific phosphorylation of LAP on liver-specific gene expression during development and under physiological stimulation.

\section{Acknowledgments}

We are grateful to Susan Taylor ard Gordon Gill (University of California, San Diego) for providing preparations of PKA and PKC, respectively. We thank Sam Maddox for preparing the manuscript.

C. Trautwein was supported by a postdoctoral fellowship from the Deutsche Forschungsgemeinschaft (Germany). Research in M. Chojkier's laboratory was supported by National Institutes of Health grants DK-38652, DK-46971, and GM-47165, and by grants from the Department of Veterans Affairs. Research in M. Karin's laboratory was supported by National Institutes of Health grants CA-50528 and HL35018. Research in T. Hunter's laboratory was supported by National Institutes of Health grant CA-39780.

\section{References}

1. Tilghman, S. M., and A. Belayew. 1982. Transcriptional control of the murine albumin/fetoprotein locus during development. Proc. Natl. Acad. Sci. USA. 79:5254-5257.

2. Panduro, A., F. Shalaby, and D. A. Shafritz. 1987. Changing patterns of transcriptional and post-transcriptional control of liver-specific gene expression during rat development. Genes \& Dev. 1:1172-1182.

3. Descombes, P., M. Chojkier, S. Lichtsteiner, E. Falvey, and U. Schibler 1990. LAP, a novel member of the C/EBP gene family, encodes a liver-enriched transcriptional activator protein. Genes \& Dev. 4:1541-1551.

4. Landschulz, W. H., P. F. Johnson, E. Y. Adashi, B. J. Graves, and S. L. McKnight. 1988. Isolation of a recombinant copy of the gene encoding C/EBP. Genes \& Dev. 2:786-800.

5. Akira, S., H. Isshiki, S. Takahisa, O. Tanabe, S. Kinoshita, Y. Nishio, T. Nakajima, T. Hirano, and T. Kishimoto. 1990. A nuclear factor for IL-6 expression (NF-IL6) is a member of a C/EBP family. EMBO J. (Eur. Mol. Biol. Organ.). 9:1897-1906.

6. Poli, V., F. P. Mancini, and R. Cortese. 1990. IL-6DBP, a nuclear protein involved in interleukin-6 signal transduction, defines a new family of leucine zipper proteins related to C/EBP. Cell. 63:643-653.

7. Chang, C.-J., T.-T. Chen, H.-Y. Lei, D.-S. Chen, and S.-C. Lee. 1990 Molecular cloning of a transcription factor, AGP/EBP, that belong to members of the C/EBP family. Mol. Cell. Biol. 10:6642-6653.

8. Cao, Z., R. M. Umek, and S. L. McKnight. 1991. Regulated expression of three C/EBP isoforms during adipose conversion of 3T3-L1 cells. Genes \& Dev. 5:1538-1552.

9. Williams, S. C., C. A. Cantwell, and P. F. Johnson. 1991. A family of C/EBP-related proteins capable of forming covalently linked leucine zipper dimers in vitro. Genes \& Dev. 5:1553-1567.

10. Descombes, P., and U. Schibler. 1991. A liver-enriched transcriptional activator protein, LAP, and a transcriptional inhibitory protein, LIP, are translated from the same mRNA. Cell. 67:569-579. 
11. Hunter, T., and M. Karin. 1992. Control of transactivation factor activity by protein phosphorylation. Cell. 70:375-387.

12. Yamamoto, K. K., G. A. Gonzalez, P. Menzel, J. Rivier, and M. R. Montminy. 1989. Characterization of a bipartite activator domain in transcription factor CREB. Cell. 60:611-617.

13. Wegner, M., Z. Cao, and M. G. Rosenfeld. 1992. Calcium-regulated phosphorylation within the leucine zipper of C/EBP $\beta$. Science (Wash. DC). 256:370373.

14. Mittnacht, S., and R. A. Weinberg. 1991. G1/S phosphorylation of the retinoblastoma protein is associated with an altered affinity for the nuclear compartment. Cell. 65:381-393.

15. Metz, R., and E. Ziff. 1991. cAMP stimulates the C/EBP-related transcription factor rNFIL-6 to trans-locate to the nucleus and induce c-fos transcription. Genes \& Dev. 5:1754-1766.

16. Trautwein, C., C. Caelles, P. van der Geer, T. Hunter, M. Karin, and M. Chojkier. 1993. Transactivation by NF-IL6/LAP is enhanced by phosphorylation of its activation domain. Nature (Lond.). 364:544-547.

17. Sambrook, J., E. F. Fritsch, and T. Maniatis. 1989. Molecular Cloning: A Laboratory Manual. Cold Spring Harbor Laboratory, Cold Spring Harbor, NY.

18. Studier, F. W., A. H. Rosenberg, J. J. Dunn, and J. W. Dubendorff. 1990. Use of T7 RNA polymerase to direct expression of cloned genes. Methods Enzymol. 185:60-89.

19. Lichtsteiner, S., J. Wuarin, and U. Schibler. 1987. The interplay of DNA binding proteins on the promoter of the mouse albumin gene. Cell. 51:963-973.

20. Laemmli, U. K. 1970. Cleavage of structural proteins during the assembly of the head of bacteriophage T4. Nature (Lond.). 227:680-685.

21. Walton, G. M., P. J. Bertics, L. G. Hudson, T. S. Vedvick, and G. N. Gill. 1987. A three-step purification procedure for protein kinase $\mathrm{C}$ : characterization of the purified enzyme. Anal. Biochem. 161:425-437.

22. Boyle, W. J., P. van der Geer, and T. Hunter. 1991. Phosphopeptide mapping and phosphoamino acid analysis by two-dimensional separation on thin-layer cellulose plates. Methods Enzymol. 201:110-149.

23. Li, L., J. N. Zhou, G. James, R. Heller-Harrison, M. Czech, and E. Olson. 1992. FGF inactivates myogenic helix-loop-helix proteins through phosphorylation of a conserved protein kinase-C site in their DNA-binding domains. Cell. 71:1181-1194.

24. Woodgett, J. R., K. L. Gould, and T. Hunter. 1986. Substrate specificity of protein kinase C. Eur. J. Biochem. 161:177-184.

25. Boyle, W. J., T. Smeal, L. H. K. Defize, P. Angel, J. R. Woodgett, M. Karin, and T. Hunter. 1991. Activation of protein kinase C decreases phosphorylation of c-jun at sites that negatively regulate its DNA-binding activity. Cell. 64:573-584.

26. Smeal, T., B. Binetry, D. A. Mercola, M. Birrer, and M. Karin. 1991. Oncogenic and transcriptional cooperation with Ha-Ras requires phosphorylation of c-Jun on serines 63 and 73. Nature (Lond.). 354:494-496.

27. Pulverer, B. J., J. M. Kyriakis, J. Avruch, E. Nikolakaki, and J. R. Woodgett. 1991. Phosphorylation of c-jun mediated by MAP kinases. Nature (Lond.). 353:670-676.

28. Lin, A., J. Frost, T. Deng, T. Smeal, N. Al-Alawi, U. Kikkawa, T. Hunter, D. Brenner, and M. Karin. 1992. Casein kinase II is a negative regulator of cJun DNA binding and AP-1 activity. Cell. 70:1-14.

29. Yamamoto, K. K., G. A. Gonzalez, W. H. Biggs III, and M. R. Montminy. 1988. Phosphorylation-induced binding and transcriptional efficacy of nuclear factor CREB. Nature (Lond.). 334:494-498.

30. Gonzalez, G., and M. R. Montminy. 1989. Cyclic AMP stimulates somatostatin gene transcription by phosphorylation of CREB at serine 133. Cell. 59:675680.

31. Boshart, M., F. Weih, M. Nichols, and G. Schutz. 1991. The tissue-specific extinguisher locus TSE 1 encodes a regulatory subunit of CAMP-dependent protein kinase. Cell. 66:849-859. 